\title{
A CONSTRUÇÃO SIMBÓLICA DO INIMIGO: O MOVIMENTO ESTUDANTIL DE 1968 PELA ÓPTICA DOS ARQUIVOS DOPS-SÃO PAULO
}

Aline Augustinho ${ }^{1}$

RESUMO: O ano de 1968 é ponto de inflexão para o Movimento Estudantil, no qual a dinâmica de relação com o Estado se torna mais violenta, a ponto de sufocar por alguns anos as manifestações de rua. O grupo que sempre abarcou questões sociais e políticas em suas pautas reivindicativas passa a se colocar frontalmente contra a ditadura após a morte de Edson Luis. A partir deste ponto, o olhar da polícia política sobre o movimento se altera e o ano passa a ser de inflexão também na forma de investigação. O ME surge como elemento político, e a identificação simbólica do grupo dentro das investigações do DOPS passa a ser feita levando em conta essa característica que não era nova, mas que passou a ser preponderante. Assim, as anotações sobre as mobilizações de 1968 são o ponto de partida para a verificação da construção simbólica do ME como grupo político pela repressão.

Palavras-chave: Movimento Estudantil. Ditadura Militar. Arquivos DOPS.

\section{THE SYMBOLIC CONSTRUCTION OF THE ENEMY: THE BRAZILIAN \\ STUDENT'S MOVEMENT IN 1968 FROM THE PERSPECTIVE OF THE DOPS- \\ SÃO PAULO'S ARCHIVES}

ABSTRACT: The year of 1968 is a turning point for the Student Movement, when the dynamics of relations with the State becomes more violent, to the point of suffocating streets organizations for a few years. The group that has always i social and political issues in their demands started to stand headlong against the dictatorship after the death of Edson Luis. From this point, the political police's look at the movement changes and this year becomes inflected also in the form of investigation. The brazilian students movement merges as a political element, and the symbolic identification of the group within the DOPS investigations

\footnotetext{
${ }^{1}$ Doutora em Sociologia pelo Programa de Pós Graduação em Sociologia da FCL-UNESP-Araraquara (2015), possui mestrado em Ciência Política em pela Universidade Federal de São Carlos - UFSCar (2010) e graduação em Ciência Sociais pela mesma universidade (2008). Endereço eletrônico: aline_cso@ yahoo.com.br.
} 
begins to be made taking into account this characteristic that was not new, but that became preponderant. Thus, the notes on the mobilizations of 1968 are the starting point for the verification of the symbolic construction of the brazilian student's movement as a political group by repression.

Keywords: Student Movement. Military dictatorship. DOPS Files.

\section{LA CONSTRUCCIÓN SIMBÓLICA DEL ENEMIGO: EL MOVIMIENTO ESTUDIANTIL BRASILEÑO EN 1968 POR LA ÓPTICA DE LOS ARCHIVOS DOPS-SÃO PAULO}

RESUMEN: El año 1968 es punto de inflexión para el Movimiento Estudiantil, en el que la dinámica de relación con el Estado se vuelve más violenta, a punto de sofocar por algunos años las manifestaciones callejeras. El grupo que siempre abarcó cuestiones sociales y políticas en sus pautas reivindicativas pasa a colocarse frontalmente contra la dictadura tras la muerte de Edson Luis. A partir de este punto, la mirada de la policía política sobre el movimiento se altera y el año pasa a ser de inflexión también en la forma de investigación. El ME surge como elemento político, y la identificación simbólica del grupo dentro de las investigaciones del DOPS pasa a ser hecha teniendo en cuenta esa característica que no era nueva, sino que pasó a ser preponderante. Así, las anotaciones sobre las movilizaciones de 1968 son el punto de partida para la verificación de la construcción simbólica del ME como grupo político por la represión.

Palavras Clave: Movimiento Estudiantil. Dictadura militar. Archivos DOPS.

\section{O grupo nos Arquivos - formas de articulação do ME segundo o aparato do Departamento de Ordem Política e Social}

$\mathrm{O}$ ano em que se completa 50 anos das maiores mobilizações estudantis brasileiras não se coloca grande produtor de novas leituras, rememorações ou exposições da memória de 1968. Ao contrário de ciclos comemorativos anteriores, como os 40 anos de 1968, em 2008, em que houve grandes manifestações, produções acadêmicas, midiáticas e um envolvimento dos próprios atores do movimento nas práticas de rememoração, 2018 tem se mostrado portador de um ciclo atípico, com raras manifestações e produções sobre o tema. Embora não exista silêncio, existe certo distanciamento dessas memórias, tão relevantes e caras à construção democrática brasileira. Talvez haja, motivada pelos recentes embates políticos nas disputas pelo poder executivo, uma mudança de olhar sobre os espaços que a esquerda ocupa - ou que deva ocupar - nas memórias nacionais. Se até 2014, com a presença da Comissão Nacional da Verdade e os estímulos do governo federal havia um grande direcionamento pelo alcance, divulgação e preservação da memória das pessoas e grupos que resistiram ou 
enfrentaram a ditadura militar, entre 1964 e 1985 (BRASIL, vol.1 e vol.3, 2014), a entrega dos relatórios finais e a conclusão das pesquisas findaram um ciclo de grande exposição da luta pela preservação da memória, verdade e justiça, e essas práticas se tornaram mais isoladas nos anos seguintes, embora não tenham deixado de existir.

Diante deste cenário, é importante pensar como as memórias sobre determinados grupos políticos se constrói e permanece - ou é apagada - parte da memória nacional. Neste trabalho, derivado de pesquisa apresentada para tese de doutoramento em Sociologia ${ }^{2}$, apresenta-se uma leitura sistematizada da produção e organização das anotações, investigações e inquéritos policiais produzidos pelo DOPS - Departamento de Ordem Política e Social ${ }^{3}$-, departamento de controle social e político desenvolvido e instalado em 1924, e utilizado pela inteligência militar entre 1964 e 1985. A proposta é salientar como um coletivo de indivíduos se converte num inimigo unificado pela repressão, o Movimento Estudantil. Por meio das anotações cronológicas e das adaptações de anotações antigas nas fichas de estudantes que participaram do movimento, é possível compreender a construção ou o desenho do olhar da ditadura sobre o inimigo social "Movimento Estudantil".

Para este artigo, a leitura sobre as estruturas do arquivo DOPS se baseiam no trabalho de Aquino (2006). A autora, que faz um relevante e intenso trabalho de interpretação das formas de organização do referido órgão da ditadura, entende que a própria estruturação das anotações nas fichas e de seu arquivamento já mostra as intenções da inteligência militar:

A visita à documentação do DOPS paulista equivale a um passeio nas demonstrações cotidianas do oficio de dominação em nosso país e a um mergulho na mentalidade repressiva, fazendo-nos constatar a 'banalidade do mal (AQUINO, 2006, p. 21).

A análise de dados das fichas catalográficas apresentadas neste artigo, no entanto, derivam de coleta realizada no Arquivo Público do Estado de São Paulo, entre 2009 e 2013. As fichas localizadas no DOPS têm informações sobre a localização dos estudantes naquele período, idade, naturalidade, filiação, cursos universitários que frequentavam, bem como dossiês que relatavam suas atividades estudantis e/ou políticas. Seus dados iniciais estão

\footnotetext{
${ }^{2}$ AUGUSTINHO, Aline M. N. A memória, o grupo e o ator. Ligações e tensões acerca da formação do conceito de identidade do Militante Estudantil de 1968. Tese de doutorado apresentada ao PPGS/UNESP FCLAr. Araraquara, São Paulo: 2015.

${ }^{3}$ O Dops (Delegacia de Ordem Política e Social), criado pela Lei n 2.034 em 30/12/1924, passa por uma reformulação em 1975 e passa a ser denominado Departamento Estadual de Ordem Política e Social, e mantém essa denominação até sua extinção em 1983 (Decreto n 20.726 de 4/3/1983).
} 
disponíveis, identificados e catalogados a partir dos documentos e pastas divididos em dois grupos de catálogos de pesquisa:

- Catálogo 1 - Ordem Política (OP), com as acusações específicas feitas pela inteligência militar, relatados contra a segurança política do país;

- Catálogo 2 - Ordem Social (OS), contendo as anotações acerca dos comportamentos julgados perigosos para a segurança social.

Para se chegar aos elementos que levam a definição simbólica do ME enquanto grupo nos arquivos foram utilizados os materiais do Arquivo Público do Estado de São Paulo, do Arquivo Geral e do Arquivo Fundo DOPS. Os documentos disponíveis para consultas podem ter os índices remissivos acessados a partir da plataforma do grupo Memórias Reveladas 4 . Para a pesquisa de mapeamento das leituras sobre o Movimento Estudantil da inteligência militar, com a chave "Estado de São Paulo/ Fonte: Delegacia de Ordem Política e Social/ Movimento Estudantil" 5, foram encontrados 1014 dossiês, textos remetentes ao índice remissivo e as fichas. Os dossiês foram separados a partir da identificação das leituras de grupos e posteriormente verificados nas salas do Arquivo.

Há um salto no número e no tipo de documentos arquivados, com um grande foco do aparato de Ordem Social nas passeatas e mobilizações de 1968 e inquéritos do Departamento de Ordem Política para os indivíduos observados como perigosos e/ou subversivos. Desarticulado após Ibiúna e com o AI-5 promulgado em dezembro de 1968, o termo ME diminui muito nos índices remissivos de investigações ou inquéritos nos primeiros anos da década de 1970, aparecendo novamente a partir de 1974.

Os dossiês elaborados pelo Arquivo Geral reúnem informações sobre os indivíduos ou grupos vigiados, mas não necessariamente tecem uma análise sobre os mesmos. Grandes eventos, como o XXX Congresso de Ibiúna produziram uma série de análises posteriores, avaliando o processo de infiltração na construção do Congresso até as prisões e os depoimentos (MARTINS FILHO, 1998, 1997). Com o refluxo do ME após o Ato Institucional nº ${ }^{\circ}$, em dezembro de 1968, as observações são orientadas para grupos menores.

\footnotetext{
${ }^{4}$ Acessado diariamente entre 02/03/2013 e 10/03/2013, nas plataformas: http://www.arquivoestado.sp.gov.br/memrev/memrev_pesquisa.php e http://www.arquivoestado.sp.gov.br/memrev/memrev_consulta.php. Verificação dos dossiês no mês de dezembro de 2013, Arquivo Público do Estado de São Paulo.

${ }^{5}$ Quaisquer outras chaves de pesquisa podem ser inseridas nas buscas das plataformas digitais Memórias Reveladas. No entanto, outras combinações traziam elementos além daqueles focados nesta pesquisa. A combinação de busca com a chave "Movimento Estudantil" Associada ao catálogo de Ordem Social e ao Estado de São Paulo trouxe o maior número de resultados de índices remissivos que não se associava a outros assuntos. 
O olhar que orienta este artigo é a dinâmica de construção dos Dossiês, que revelam o foco e a abordagem da inteligência da repressão para a manutenção da ordem então instituída. Delineia-se um percurso através dos títulos e do tipo de documento armazenado em cada Dossiê. Dos índices remissivos localizados a partir das chaves utilizadas na pesquisa, estruturou-se a análise de grupos a partir da identificação (o título), da fonte do levantamento, (o arquivo geral, a seção de ordem política ou a seção de ordem social), e o tipo de material que compunha o levantamento (noticias de jornais, jornais dos meios estudantis, panfletos, comunicados e material mimeografado produzido pelas entidades estudantis, relatórios oficiais - estes produzidos por órgãos das Forças Armadas para o DOPS - e inquéritos). Após o mapeamento dos índices remissivos e a identificação de cada material, aqueles demonstravam a identificação de grupo no $\mathrm{ME}$ foram abertos e fotografados no Arquivo Público do Estado de São Paulo, e parte do aqui reproduzida.

Os arquivos são produzidos pelos DOPS em 3 segmentos: arquivo Geral, para qualquer individuo/situação que de alguma forma possa quebrar leis regras sociais, Ordem Política e Ordem Social. É possível verificar que a própria origem dos inquéritos, num desses três departamentos, sugere uma visão e um tipo de orientação para conter as mobilizações

Identificaram-se cinco grupos analíticos, subdivididos a partir do tipo de ação empreendida observada pelo DOPS. Importante observar que estes arquivos foram construídos a partir de uma estrutura linear, ou seja, a partir das investigações do aparato repressor acerca das atividades estudantis na medida em que chegavam a seu conhecimento. Manteve-se a linearidade temporal, ao mesmo tempo em que se agruparam os temas em seções a partir das similaridades do tratamento e da identificação feita pelo DOPS Departamento de Ordem Social. Assim, tem-se 5 sessões que avaliam 10 grupos de ação estudantil:

\section{Quadro 1 - Sessões de divisão de grupos da ação estudantil}

\begin{tabular}{|c|c|}
\hline \multirow{2}{*}{$\begin{array}{c}\text { A organização do } \\
\text { Movimento estudantil }\end{array}$} & Dinâmica do Movimento Estudantil e questões Universitárias \\
\cline { 2 - 2 } & O Movimento Estudantil Secundarista \\
\hline \multirow{2}{*}{ Estruturais } & Atividades localizadas de Diretórios Acadêmicos, Centros \\
\cline { 2 - 2 } & Acadêmicos, DCEs \\
\cline { 2 - 2 } & Atividades de entidades estudantis (neste caso quase sempre \\
& versavam sobre a UNE) \\
\hline
\end{tabular}




\begin{tabular}{|c|c|}
\hline \multirow{2}{*}{ Por Regiões } & $\begin{array}{c}\text { O Movimento Estudantil em grupos regionais específicos: } \\
\text { Regiões, Estados, Cidades, Universidades locas e cursos } \\
\text { específicos }\end{array}$ \\
\hline \multirow{3}{*}{ Atividades Políticas } & Orientação Ideológica : as esquerdas e o ME \\
\cline { 2 - 3 } & Associação com a luta armada - AP, VPR, Var Palmares \\
\cline { 2 - 3 } & Lutas Populares: Campesinato, Sindicalismo \\
\cline { 2 - 2 } & O Histórico Do ME \\
\cline { 2 - 2 } & A Reconstrução \\
\cline { 2 - 2 } & O ME Revolucionário fim dos anos 1970 e início dos anos 1980 \\
\hline
\end{tabular}

Fonte: Augustinho (2018).

A relação Dossiês/Fichas /Relatório levantadas neste quadro e apresentadas no tópico a seguir revelam construções mais aproximadas ou mais gerais, associando um mesmo dado (um evento, uma prisão, uma passeata) ao indivíduo, nas fichas, à grupos de indivíduos nos relatórios, e ao panorama geral do ME nos Dossiês.

Observa-se uma tendência de associação à riscos para a Ordem Política ou para a Ordem Social segundo o nível mais aproximado ou mais geral da análise: os textos sobre ações subversivas de indivíduos tendem num primeiro momento a associar sua ação às possibilidades de risco à ordem social. Quando esta mesma ação é ligada a um grupo ou entidade estudantil, ela fica despersonalizada, e passa a pertencer ao grupo e não mais ao agente, de modo a oferecer risco à Ordem Política. Observa-se tal desenrolar na fonte de produção de um documento baseado na mesma ação, na identificação como Arquivo Ordem Social para fichas individuais e de ações de pequenos grupos ( 3 a 5 pessoas), provenientes também de delegacias locais, e identificação como Arquivo Ordem Política, nos Dossiês e Relatórios sobre a ação desses mesmos indivíduos associados ao ME, à entidades representativas clandestinas ou grupos de esquerda.

Aplicados a uma percepção temporal, pode-se também compreender esses modelos de apreciação investigativa em dois momentos: como análises do fato presente, nas fichas de prisões e relatórios de manifestações-relâmpago; e reinterpretações da ação, quando alguns dias, semanas ou meses após um fato isolado, o mesmo é associado a um grupo maior e reinterpretado à luz dessa nova associação. 
O objetivo aqui não é de analisar o conteúdo de cada documento, mas a intenção do aparato investigativo na construção de cada um dos três modelos, que culminará na identificação simbólica de grupo feita pelo mesmo sobre o ME. Desta forma, com o intuito de observar a construção do conceito de grupo, analisa-se as anotações identificadas como investigações do grupo ME entre 1968 e 1983. Neste caso, o importante são as associações feitas pelo DOPS na organização de suas análises, pelo título do documento, a atenção aplicada a determinada linha investigativa, pelo número de relatórios produzidos sob o mesmo título (identificados na forma numérica do acesso ao documento), e a data de produção, que revelam os movimentos de maior ou menor concentração investigativa sobre o ME ao longo do período entre 1968 e a redemocratização. Dos dossiês que tratam apenas do ME sem associações com outro tema, encontramos 624 processos de investigação entre 1969 e 1982 . A grande maioria, 618, produzidas pelo Arquivo Geral.

Em 1968, as grandes mobilizações estudantis, prisões, processos judiciais, o fichamento e controle dos presos em Ibiúna foram observados pelo departamento de Ordem Social. Assim, observa-se a mudança nos parâmetros da repressão, seu olhar sobre os estudantes. Em 1968, um risco à ordem social, e posteriormente, sem categorizá-los como um movimento político, apenas as ações individuais. O ritmo de produção dos dossiês também revela a dinâmica da repressão sobre o Movimento como grupo. Não há registro no Arquivo Geral em 1969, 5 em 1970, apenas um em 1971 e 1972, 2 processos em 1973. Os números crescem acentuadamente a partir de 1974:

Quadro 2 - Fluxo de Produção de Fichas DOPS 1969-1983

\begin{tabular}{|l|l|}
\hline \multicolumn{1}{|c|}{ Ano de investigações } & \multicolumn{1}{c|}{ Dossiês Arquivo Geral } \\
\hline 1969 & -- \\
\hline 1970 & 5 \\
\hline 1971 & 1 \\
\hline 1972 & 1 \\
\hline 1973 & 2 \\
\hline 1975 & 14 \\
\hline 1976 & 28 \\
\hline
\end{tabular}




\begin{tabular}{|l|l|}
\hline 1977 & 176 \\
\hline 1978 & 130 \\
\hline 1979 & 15 \\
\hline 1980 & 4 \\
\hline 1981 & 14 \\
\hline 1982 & 2 \\
\hline 1983 & -- \\
\hline
\end{tabular}

Fonte: Augustinho (2018).

Por que essa mudança? O repúdio à morte do estudante Alexandre Vanucchi Leme é um dos pontos que impulsionou a rearticulação do ME nas ruas, em protestos. Mas, diante das fichas, veremos que mesmo com a clandestinidade e a prisão de parte das lideranças estudantis em 1968, o movimento manteve-se articulado, embora em menor escala e não paralisado totalmente após o AI-5.

Os Dossiês revelam um tipo de investigação interna ao movimento, a partir de elementos infiltrados, compostos em sua maioria por materiais produzidos pelo próprio $\mathrm{ME}$, como teses, panfletos, faixas e cartazes, revelando o controle das atividades do grupo, sem necessariamente terminar em inquéritos ou investigações policiais. Portanto, entende-se que havia a punição para a perturbação da ordem estabelecida ou pelo comportamento subversivo praticado em grupo, porém, na medida em que as entidades estudantis para o governo militar não existiam oficialmente desde 1964 (notadamente nos inquéritos, a identificação da "ExUNE", "Ex- UEE"), as sanções eram aplicadas ao indivíduo e não ao grupo. A simbologia do grupo, no entanto, era forte o suficiente para que inquéritos de identificação de estudantes e de seu comportamento fossem instaurados pela simples notificação de associação com qualquer mobilização estudantil. O grupo, para a inteligência expressa no DOPS, não existia, já que era ilegal. Seu símbolo existia. E o controle político, então, passava a ser individual.

Há também dossiês de observação produzidos pelo DOPS sobre as atividades estudantis e investigações específicas produzidas pelas Forças Armadas. As cartas de próprio punho e declarações de retratação sobre comportamentos subversivos é um dos fatores que mostram o processo de coerção sobre os estudantes e está presente em inúmeras pastas do departamento de Ordem Social. A proposta de esclarecimentos cria a coerção e a punição já no ato de materializar uma retratação formal que ficaria nos arquivos. Há um imenso foco nas 
atividades da USP (Universidade de São Paulo), provavelmente, pela proximidade geográfica ao DOPS - São Paulo, e também pela centralidade da organização das mobilizações estudantis, mas há dossiês sobre a PUC, Unicamp, e mobilizações em cidades do interior, como Ourinhos, Presidente Prudente, Bragança Paulista, Votuporanga, São Carlos, Araraquara, Ilha Solteira, Bauru, Marília e também outros estados, como Minas Gerais, Rio de Janeiro e Rio Grande do Sul. Os temas com maior atenção nesses documentos são a associação com a luta sindicalista a partir de 1976 (5 ocorrências), as mobilizações pela reconstrução da UNE (com 12 ocorrências), os Congressos Estudantis (8 ocorrências) e referências de grupos estudantis à memória de 1968 (10 ocorrências).

Enquanto os Dossiês são levantamentos mais gerais, os autos de sindicância descrevem internamente o processo de averiguação de um determinado movimento levantado pelos dossiês. Neste sentido, os indivíduos são investigados separadamente em decorrência de seu vinculo com o grupo. Os autos de sindicância não são, geralmente, sobre eventos, acontecimentos, mas produções mais específicas e têm dados mais concretos sobre a atuação, posicionamento, endereço, familiares, matriculas na universidade, notas, etc. Para o estudo empírico elencou-se o grupo que teve maior número de anotações e/ou indiciamentos posteriores à Ibiúna, mas em que as acusações feitas pelo DOPS retomassem essa participação. Assim, chegou-se a 18 estudantes brasileiros, mais um estudante argentino imediatamente indiciado pela presença em Ibiúna. As trajetórias da ação política desses atores identificada pelos indiciamentos serão dispostas a seguir.

\section{Inquéritos e Fichas: a identificação do grupo}

Entre os presos em Ibiúna, 11 estudantes foram imediatamente enquadrados na Lei Segurança Nacional com processo na Justiça Militar de número $14 / 68^{6}$, e por isso, presos em flagrante delito ${ }^{7}$. Tratava-se da identificação daqueles que à repressão pareciam ser os mais ativos, que articulavam mais ações contra a ditadura militar, com exceção de Juan Sander, argentino, acusado de promover o comunismo no Brasil. Todos os demais 719 delegados foram enquadrados num segundo processo, sob a acusação de atividade política clandestina,

\footnotetext{
6 "Indiciados no IP n15/68 (Ibiúna), por infração na Lei de Segurança Nacional, por ter participado do $30^{\circ}$ Congresso da Extinta UNE. Autuado á justiça militar aos 18/10/1968. Conforme oficio $\mathrm{n}^{\mathrm{o}}$ 358, os epigrafado tiveram declarada extinta sua punibilidade na data de 023.02.1973".

${ }^{7}$ Segundo dados do Relatório Operação Ibiúna. Indiciados em $1^{\circ}$ flagrante, Luiz Travassos Gonzaga da Rosa, Augusto Guilher Ribeito Ribas, Vladimir Gracindo Soares Almeida, José Dirceu de Oliveira e Silva; em $2^{\circ}$ flagrante, Walter Aparecido Cover, Omar Laino, Helenira Rezende de Souza Nazareth, Franklin de Souza Martins, José Benedito Pires Trindade, Marcos Aurélio Ribeiro; em $3^{\circ}$. Flagrante, o argentino Juan Antonio Sander. Páginas 130 e 131 do relatório.
} 
processo $n^{\circ} 15 / 68$ - este é o processo em torno do qual giram todas as investigações e levantamentos da Operação Ibiúna, e ao qual se retomava sempre que outro processo era anexado na ficha individual.

A punibilidade de todos os envolvidos neste processo foi prescrita em 23.02.1973 conforme oficio $n^{\mathbf{o}} 358$. De todos os processos judiciais sofridos pelos estudantes, era o de Ibiúna o que o identificava e colocava num grupo específico, o ponto de partida para o delineamento das acusações e dos inquéritos subseqüentes. As ações posteriores enquadradas na LSN tinham como agravante nos processos judiciais sua presença no IP 15/68, como demonstrado na anotação da ficha de Carlos Vainer: “08/06/1971 Segundo documento desta data, figura relacionado no depoimento do subversivo "Alexandre Lyra de Oliveira", militante do GPM do MR-8/GB, como um dos elementos do Movimento Estudantil de 1968/69”.

Entre 1969 e a data da anotação, o referido agente já havia tido duas ordens de prisão expedidas pela Justiça Militar, banido do território Nacional pela associação ao sequestro de Enrico Bucher, além de repetidas incursões nos prédios de DOPS para esclarecimentos, em processos nem sempre detalhados no histórico. Porém, a menção ao XXX Congresso na fala de outro agente era motivo suficiente de anotação separada em seu perfil. Essa participação era sabida e confirmada, mas toda menção era repetidamente adicionada.

O estudo prosopográfico mostra a construção burocrática da repressão sobre Movimento Estudantil, as formas de organização dos dispositivos de investigação de ações subversivas até a instalação dos Inquéritos Policiais. A partir daí, os dados eram enviados a Justiça Militar e somente seus pareceres voltavam a integrar o histórico de cada estudante. A repressão materializada nos DOPS vigiava, levantava dados e a partir deles identificava grupos de ação no Movimento Estudantil, mas a ação punitiva, nos documentos, era sempre da Justiça Militar.

Figuram os procedimentos legais e ocasiões de torturas não parecem nem nos depoimentos prestados durante prisões e apreensões, sendo anotados apenas fragmentos deles, de acordo com o direcionamento de investigação que se projetava para o indivíduo em questão. De todos os documentos analisados, apenas dois mencionam a passagem dos chamados "marginados" pela Oban. Entende-se que esta parte dos Arquivos foram construídas para caberem nos dispositivos legais que levariam à investigações mais profundadas, e talvez, a punibilidade..

Entre 719 estudantes fichados após a prisão pela participação no XXX Congresso da UNE em Ibiúna, houve várias investigações paralelas que os encaixavam em grupos 
diferentes: as lideranças, os mais perigosos (separados entre homens e mulheres) tentando estabelecer as relações entre os indivíduos que pudessem nortear o Movimento Estudantil. A partir da comparação prosopográfica como indicada no quadro anterior, pode-se separar dois grupos com modelos de abordagens distintas: um grupo de 17 delegados cujos indiciamentos no processo 68/15 foram levados a cabo pela Justiça Milita,r resultando em processos criminais e/ou prisões, e o grupo mais amplo, que não teve outros desenrolares judiciais associados àquele processo.

Nas fichas catalográficas, estes 17 indivíduos se destacam por conter um grande número de anotações no histórico associadas às articulações paralelas às atividades estudantis, como a luta armada. As fichas catalográficas estão aqui reproduzidas segundo os informes das delegacias locais captadas pelo DOPS. Na transcrição para a tese e para este artigo, alterações ortográficas mínimas foram introduzidas a fim de adequá-las às normas gramaticais correntes, entretanto, sem haver qualquer prejuízo para seu conteúdo, passível de verificação do documento original a partir do índice remissivo no Arquivo Público do Estado de São Paulo/Arquivo DOPS.

Essas fichas são baseadas naquelas produzidas nas prisões de 31 de Outubro de 1968, em Ibiúna. Naquele momento, três blocos de identificação foram confeccionados: um bloco geral, com a identificação por nome, idade, endereço, filiação e curso, com todos os 719 estudantes presos; um bloco de identificação a partir do gênero, com os mesmos dados, uma pasta para identificação feminina e uma pasta para identificação masculina, e um terceiro bloco, com a identificação dos estudantes considerados mais perigosos, também separados por gênero, contando com 89 identificações masculinas e 27 identificações femininas (Augustinho, 2010).

As fichas aqui reproduzidas são construções de análise internas aos DOPS, que mesclam as atividades "subversivas" dos agentes com os resultados dos processos que corriam na Justiça Militar, tendo como ponto de partida o processo 15/68, referente à prisão em Ibiúna. Desta forma, cada ficha de análise interna possui uma numeração, nem sempre legível, que remonta à primeira identificação feita após Ibiúna, aparentemente organizada alfabeticamente, mas com erros de execução do próprio DOPS. Segundo o processo escolhido nesta pesquisa, a seleção da análise das fichas de agentes com o maior número de anotações vinculadas à manifestações estudantis não diretamente ligadas à grupos de esquerda, segue a seguinte apresentação: ordem alfabética, numeradas segundo a ordem em que aparecem na pesquisa. É preciso notar que no arquivo, as fichas doravante identificadas 
como "análise interna" ao DOPS estão organizadas alfabeticamente, num volume único para o conjunto geral dos 719 estudantes.

É importante observar que todas as anotações, ainda aquelas classificadas como terrorismo, são associadas ao Movimento Estudantil e as investigações giram em torno do movimento. Para o estudo prosopográfico e a verificação das linhas propostas acima, destacou-se o grupo de estudantes que tiveram Inquéritos Policiais instaurados e levados até a Justiça Militar. São eles: Carlos Vainer; Carlos Leopoldo Teixeira Paulino; nº 123, Cid de Queirós Benjamim "Vitor" "Levy" "Billi" "Uilli"; Irene Cortina; José Vieira Loguércio (Rio Grande do Sul, 31 anotações entre 1968 e 1972); José Dirceu de Oliveira e Silva; Franklin de Souza Martins (Valdir, Miguel); Gilberta Aarão Reis; Iara Gouveia ; Jose Roberto Arantes de Almeida; Juan Antonio Sander; Jun Nakabayashi; Maria Augusta Thomaz; Lyvia Rossi Rego; Neide Cousin; Ernesto de Mello Levy; Vladimir Gracindo Soares Palmeira . Neste artigo, três dessas fichas serão reproduzidas, as de Carlos Vainer, Cid Benjamin e Gilberta Aarão. ${ }^{8}$

Estas fichas foram produzidas entre 1971 e 1972 (apesar de não terem data de confecção, nota-se pela idade marcada dos fichados, em comparação às suas datas de nascimento). As fichas foram construídas em 1971 de forma mais detalhada do que as fichas feitas no momento da prisão, que continham os números de documentos pessoais, filiação, naturalidade e universidade. Mas ainda assim, o evento Ibiúna o é fator central, e os eventos anteriores a 1968 (os mais antigos datam de 1964) giram em torno da construção de um elemento subversivo ligado ao Movimento Estudantil, principalmente, e a grupos armados de forma secundária. Alguns indivíduos, como Gilberta Aarão Reis e Carlos Vainer, tinham anotações de investigação anteriores ao evento de Ibiúna, mas todos os ligados ao ME foram compilados com um direcionamento intencional. As fichas levantadas, transcritas de maneira simplificada em relação ao quadro original, são as seguintes ${ }^{9}$ :

Ficha Catalográfica n ${ }^{\circ}$ 1: Carlos Vainer

Codinome: "Valentim" "Felix" "Juraci" "Peri"

\footnotetext{
${ }^{8}$ Expressa-se aqui o profundo respeito aos estudantes listados neste artigo. Ainda que as fichas estejam dispostas num Arquivo Público e de acesso aberto, as anotações revelam parte da história e memória pessoal de cada um deles, além de fazerem parte das memórias nacionais. Memórias que podem ser dolorosas e traumáticas. O ME era visto como organismo autônomo pela repressão, mas composto por pessoas com intenções, leituras, desejos e sonhos individuais, e é preciso também compreendê-los não apenas como atores do $\mathrm{ME}$, mas em sua dimensão humana, individual e particular. Assim, a intenção não é expor as atividades dos estudantes, mas entender a leitura que a repressão fazia dos mesmos por meio das anotações.
}

\footnotetext{
${ }^{9}$ Numeração dada para exposição no artigo. No arquivo, elas aparecem sem essa numeração.
} 
Rio de Janeiro, 24 anos 16-07-1948

Estudante mora no Rio de Janeiro

Estudante da Faculdade de Economia e Administração da Universidade Federal do Rio de Janeiro

Indiciado no IP n15/68 (Ibiúna), por infração na Lei de Segurança Nacional, por ter participado do $30^{\circ}$ Congresso da Extinta UNE. Autuado á justiça militar aos 18/10/1968 23.02.1973 - Conforme oficio $\mathrm{n}^{\mathrm{o}} 358$, o epigrafado teve declara extinta sua punibilidade. 21/10/1968 Nesta data foi expedido mandato de prisão preventiva contra o fichado, determinada pelo Dr. Juiz Auditor da $2^{\mathrm{a}}$. RN

14/01/1971 - Informação do Diário da Noite: por decreto presidencial, foi banido do território nacional, tendo em vista que seu nome consta da relação apresentada pelos seqüestradores do Embaixador Suíço - Enrico Bucher, para ser trocado pela liberdade do diplomata estrangeiro 23/02/1973 - Conforme ofício n358 da 2a . Auditoria o epigrafado teve declarada extinta sua punibilidade, pela prescrição da ação penal, já transitada em julgado, no caso de Ibiúna 13/02/1973 - Informa a PM do Estado de São Paulo, conforme declarações da ex-terrorista Solange Lourenço Gomes, em julho de 1971, o julgado, juntamente com Carlos Augusto Zílio, participava de ações de aliciamento de subversivos através do sexo. Era coordenador de grupos no meio estudantil, participou de vários assaltos [...]

Menção ilegível a DI-GB (MR-8)

13/10/1968 - foi preso em Ibiúna

23/10/1968 - Figura em uma relação de elementos [... ilegível] com prisão preventiva decretada pela justiça de São Paulo

10/11/1968 - O "marginado" que se encontrava preso em São Paulo a disposição do Conselho [...] da $2^{\text {a }}$. Auditoria Militar [...] por haver participado do XXX Congresso da Ex-UNE , teve habeas-corpus impetrado em seu favor, regido pelo Superior Tribunal Militar

17/12/1968 Segundo documento aqui existente, [...] $\mathrm{n}^{\circ}$ 193/68, do Delegado Adjunto da Ordem Política, onde comunica que o marginado continuará preso em São Paulo 1969 - Foi eleito por chapa encabeçada por Carlos Alberto Diniz, o diretor da Une 17/03/1969 - Transcrição da unidade de prisão da Primeira Auditoria da Aeronáutica, pelo Major Edson Brandão Guimarães, da secretaria de Saúde do Hospital Central da Aeronáutica, manda, na forma da lei, e com fundamentos no Art. 156 do Código da Justiça Militar, seja preso e recolhido, incomunicável, o marginado, contra o qual se estão procedendo às 
investigações policiais para apurar-se o roubo de uma metralhadora, ocorrido neste hospital, cuja co-autoria lhe é atribuída

20/04/1970 Foi Preso e encaminhado ao primeiro Codi, onde declarou que no primeiro semestre de 1968, foi recrutado por Franklin de Souza Martins a participar da organização comuno-terrorista identificada pela sigla DI-GB (Dissidência Comunista da Guanabara), quando passou a usar os codinomes Valentin, Feliz, Juraci, Peri, e ser o responsável pela FCM (Frente de Camadas Médias) da Organização, tendo participado de três expropriações de carros, um "ponto" com elementos da "VPR", na Rua Henrique Dias (Estação da Rocha) e qu7e estava armado com um revolver "38”, que não foi usado, recebendo entretanto um ferimento à bala no pé direito. Residia num quarto (aparelho) da Travessa da Soledade, $\mathrm{n}^{\circ} 10$, em companhia de outro elemento \{ilegível\}

07/05/1970 - Foi recolhido ao X.E, à disposição do DOPS.

06/06/1970 - Foi transferido para o "CODI"

21/07/1970 - Foi expedido pela $2^{\circ}$ Auditoria Militar da Marinha, mandado de prisão preventiva contra o epigrafado

22/07/1970 - Tomou parte do assalto ocorrido no dia 24/03/1970, contra a Kombi coletora de valores do Banco Irmãos Guimarães, fato este ocorrido na Rua Almirante Gavião

17/03/1970 - Elemento de cúpula da Dissidência [ilegível] políticas e armadas da organização. O indiciado é elemento perfeitamente identificado com o movimento terrorista subversivo no Brasil 28/09/1970 - Segundo documento da $2^{\mathrm{a}}$. Auditoria da Marinha, $\mathrm{n}^{\circ}$ 1870, figura indiciado como incurso nas sanções do artigo no 42 do Dec-Lei no 898/69

13/01/1971 Foi Banido do território Nacional em troca da liberdade do Embaixador da Suíça, pelo Dec. $\mathrm{N}^{\circ} 68050$

22/03/1971 - Apesar de banido do Território Nacional, o DR. Juiz Auditor da 1 a . Auditoria do Exército da $1^{\circ} \mathrm{CJM}$, manda que seja recolhido preso, à disposição deste Juízo 30/04/1971 - Segundo documento desta data, do $1^{\text {o }}$ Exército $-2^{\mathrm{a}}$. Seção, fez parte de uma mini-conferencia na qual foram citadas as seguintes deliberações: criação de um G.F. (Grupo de Foco), dar maior ênfase ao trabalho operário e menos ao ME (Carrear is recyrsis di M.E. oara i FTC e para G.F.) Nestas linhas de ação passa a ser conhecidas como "Resolução" 08/06/1971 - Segundo documento desta data, figura relacionado no depoimento do subversivo "Alexandre Lyra de Oliveira", militante do GPM do MR-8/GB, como um dos elementos do Movimento Estudantil de 1968/69 
26/07/1971 - Através de memorando n 451/71, datado de março, da Delegacia de Roubos e Furtos, consta que o epigrafado estaria preso naquela dependência

08/10/1971 - Figura nas declarações prestadas pelo subversivo Marcos Dantas Loureiro, como um dos integrantes da Dissidência Estudantil do PCBR, tendo participado das atividades de rua. Podendo citar a "Passeata do enterro do Estudante EDSON LUIS" 10/12/1971. Figura relacionada, nas declarações prestadas pelo subversivo Cesar de Queiros Benjamim, como um dos participantes do assalto ao IFP (instituto Feliz Pacheco), de Madureira

23/02/1972 - Segundo Registro $n^{\circ}$ 1841/72, deste DOPS, compareceu a esta dependência o Sr. João Alves da Silva Filho, gerente do Banco Brasileiro de Descontos S/A, para comunicar que após examinar os álbuns fotográficos desta Delegacia, reconheceu o epigrafado como um dos elementos que assaltaram aquele estabelecimento bancário

Ficha Catalográfica no 2: Cid de Queirós Benjamim "Vitor" "Levy” "Billi" "Uilli" Nascido no Recife, 24 anos Residência Rio de Janeiro

Organização - Une

Estudante da Faculdade de engenharia da Universidade Federal do Rio de Janeiro. Indiciado

Indiciado no IP n15/68 (Ibiúna), por infração na Lei de Segurança Nacional, por ter participado do $30^{\circ}$ Congresso da Extinta UNE. Autuado á justiça militar aos 18/10/1968 23/02/1973 - Conforme oficio $n^{\circ} 358$, o epigrafado teve declara extinta sua punibilidade. 6/03/1970 - Indiciado em Inquérito Policial instaurado a respeito do seqüestro do embaixador dos EE.UU - Sr. Elbrick, ocorrido em setembro de 1969. Foi denunciado pela Promotoria da $1^{\text {a }}$. Auditoria, em 5/3/1970 e enquadrado no art. 16 do Dec-Lei 314 e 25 do Dec-Lei 510, da Nova Lei de Segurança Nacional

15/06/1970 - Informação do Diário da Noite: Acusado de participar do seqüestro do embaixador Charles Elbrick, enquanto estudante, integrava a dissidência da Guanabara. Já foi qualificado e interrogado no Processo que está em fase sumária [...] com a inscrição das testemunhas arroladas pela defesa. Está, também, respondendo ao Processo na $2^{\mathrm{a}}$. Auditoria da Marinha referente ao estouro de um "aparelho" , à rua Montevidéu, apto 2025, na Guanabara. Liberado em troca da vida do embaixador Von Holleben e exilado na Argélia 23/02/1973 - Conforme Ofício $n^{o} 358$ da $2^{\text {a }}$. Auditoria [...] o epigrafado teve declara extinta sua punibilidade, pela prescrição da ação penal [...] 
15/02/1973 - Informa a PM do Estado de São Paulo, Em outubro de 1969, participou das seguintes ações: assalto ao bar do Castelinho; ao sentinela do hospital central da Aeronáutica; a Agencia de Bonsucesso do Banco de Crédito [ilegível]

Informação do DOPS da Guanabara:

1968 - Participou de vários movimentos estudantis na Faculdade. Era da segurança pessoal de Vladimir Palmeira, nas passeatas dos (50.000) e (100.000)

1969 - Ingressou na Dissidência Estudantil da Guanabara “[...] Frente do Trabalho Armado (FTA). Tomou parte no ilegal XXX Congresso da Ex-UNE, tendo sido indiciado em inquérito no DOPS de São Paulo, como incurso no art. 36 da Lei de Segurança Nacional. Era um dos mais perigosos elementos da referida "Dissidência" devido sua grande periculosidade. Figura indiciado nos seguintes inquéritos da [...]: Inquérito 50/69 2 $2^{\mathrm{a}}$. Auditoria da Aeronáutica da $1^{\circ}$ RN, para apurar o assalto praticado contra a Agencia do Banco Crédito Territorial S/A, tendo sido denunciado como incurso no art. 25 do Dec-Lei n) 510/69, Inquérito $n^{\circ}$ 97/69, aforado à $1^{\mathrm{o}}$ Auditoria do Exercito da $1^{\mathrm{a}}$. CJM, para apurar o assalto ao carro coletor de valores do Banco Mercantil de Niterói S/A. Inquérito $\mathrm{n}^{\mathrm{o}}$ 111/69, aforado a $1^{\mathrm{a}}$. Auditoria da Marinha da $1^{\mathrm{a}}$. CJM, para apurar assalto praticado contra o carro coletor de valores do Banco Português do Brasil S/A, Inquérito $\mathrm{n}^{\circ}$ 125/69, aforado à $2^{\mathrm{a}}$. Auditoria do Exercito para apurar o assalto levado a efeito contra a residência do deputado Federal Dr. Magalhães de Almeida, tendo sido denunciado como incurso no art. 25 do Dec-Lei $n^{\circ}$ 510/69, sendo expedido mandado de Prisão contra o mesmo

17/11/1969 - Participou de assalto ao I.F.P de Madureira, onde foi retirada grande quantidade de formulários para carteira de identidade

1970 - Foi indiciado nos seguintes inquéritos: $n^{\circ}$ 15/70, para apurar o atentado levado a feito pelo epigrafado a outros elementos, contra policiais desta delegacia., quando caiu ferido um policial.; Inquérito $\mathrm{n}^{\circ} 51 / 70$, para apurar o assalto praticado pelo epigrafado, que já então integrava o "Grupo de fogo da Dissidência Comunista" [foco*], que havia instituído a "Frente de Trabalho Armado/FTA”, contra a Agencia Ramos, da União de Bancos Brasileiros S/A; inquérito $\mathrm{n}^{\circ} 72 / 70$, para apurar o assalto levado a efeito contra a Kombi transportadora de valores do Banco Irmãos Guimarães S/A

04/01/1970 - Figura em relação de elementos subversivos, indiciados em IPM, instaurados na Marinha e que se encontram foragidos

19/03/1970 - Segundo relatório do inquérito referente ao "aparelho" subversivo da Rua Montevidéu, o epigrafado figurava entre os líderes que conseguiram evadir-se 
08/05/1970 - Foi preso e recolhido ao X.E, para averiguações, indiciado no inquérito n4/70, para apurar o assalto levado a efeito contra o Bar Castelinho[...] +22 citações no DOPS (inquéritos e depoimentos de outras pessoas)

21/11/1972 - Figura em uma relação de elementos banidos que frequentaram grupos de guerrilha em Cuba

Ficha Catalográfica nº 3: Gilberta Aarão Reis

Rio de Janeiro - RJ

Estudante Letras

Indiciada no inquérito $15 / 68$

23.10.1968 - Expedido mandado de prisão pela $2^{\mathrm{a}}$, auditoria

1973. Extinta punibilidade..

29 anos, 17-09/1943

Informações da PM de São Paulo

Indiciado no IP n15/68 (Ibiúna), por infração na Lei de Segurança Nacional, por ter participado do $30^{\circ}$ Congresso da Extinta UNE. Autuado á justiça militar aos 18/10/1968 23/02/1973 - Conforme oficio $n^{\circ} 358$, o epigrafado teve declara extinta sua punibilidade.

Novembro/69 É intimamente ligada ao grupo chefiado por Joaquim Camara Ferreira, autor do sequestro do embaixador americano, do qual, também participou João Lopes salgado. É irmã de Daniel Aarão reis Filho. Era encarregada de alugar aparelhos para a organização.

Informação do DOPS Guanabara

06/061967 Nesta data a epigrafada tomou posse como $1^{\text {a }}$. Secretaria na Faculdade Nacional de Filosofia, no Diretório acadêmico

10/10/1967 Figura na relação de estudantes da UERJ que participou de piquetes contra o pagamento de anuidades

Foi encaminhada para o DOPS GB após Ibiúna e por isso figurou no Grupo daqueles que teve decretada a ordem de prisão. Esteve em manifestação no centro em dezembro de 1968.

Maior foco nas ações estudantis entre 1968 e 1969

Figura em citações e depoimentos

16 anotações até 1971 (exceto o de 1973 sobre a exclusão da punibilidade.)

$\mathrm{Na}$ apresentação destas fichas, nota-se que a estrutura de perseguição aos estudantes não se inicia em 1968, ela está presente desde o início da década, mesmo quando o país ainda estava sob uma democracia. Entretanto, a forma de tratamento dado começa a se alterar em 
1966 quando o ME expressa de forma mais vivaz o seu posicionamento político para além das demandas universitárias. A partir de então, alguns dos indivíduos do ME, normalmente as lideranças ou aqueles que tinham ligações com o PCB, passam a ser observados mais atentamente.

Porém, a ameaça possível era individual, segundo o potencial visto nas ações da cada um. É a partir de 1968 e principalmente depois dos relatórios "Ibiúna" e "Operação Ibiúna" que a simbologia do grupo ME como inimigo iminente se altera. De acordo com as fichas e os relatos dos atores, havia ainda a separação entre a periculosidade dos indivíduos e entre o empenho na captura de líderes e de elementos das bases estudantis. Mas as anotações mostram que as ações individuais eram encaixadas nas análises produzidas de modo a traçar uma linha de ação que se pudesse identificar para o ME. Até mesmo as ações nitidamente relacionadas aos grupos de luta armada são, em algum momento nas anotações do histórico, associadas às táticas do Movimento Estudantil.

O conceito adentra as investigações da década de 1970 e mesmo com as articulações estudantis voltadas para outros objetivos, como a reconstrução das entidades e as investigações são redirecionadas ao ME de 1968 como fundamento das ações subsequentes. Por exemplo, ano a ano na década de 1970 há nos arquivos o controle de ingresso e trancamento de matrículas nas universidades, pedidas pelos delegados locais e fornecidas pelos reitores/diretores das universidades, mas se um novo grupo se sobressaia nas articulações, a anotação seguia para as pastas relativas ao ME de 1968.

Depreende-se também que a forma investigativa passa da espreita e movimentação externa até 1966, na qual os dossiês estruturam-se sobre o que se "viu" ou se "ouviu", e passasse para a investigação interna, com a presença de informantes/ou agentes infiltrados, dadas as informações internas repassadas aos oficiais momentos após as reuniões, via rádio, ou horas depois, em relatório na delegacia. Presumem-se, entretanto, tais ocorrências pelo estilo do relato dos fatos observados e pela rapidez, mas não nos arquivos qualquer indicação para isso, nem mesmo nos relatórios sobre a queda de Ibiúna.É preciso pensar que, arquivos da repressão aos quais se tem livre acesso foram escolhidos para serem abertos, em contraposição aos outros ainda lacrados, os que foram destruídos ou desaparecidos, e, portanto, ter cuidado ao interpretar as informações ali dispostas. Muitas informações são desencontradas, conflitam-se entre a versão paulista e os ofícios de outras delegacias, sendo preciso comparar cada histórico em todas as pastas que fazem referência a um mesmo indivíduo/grupos. 
Alguns dos que foram para a luta armada tinham suas atividades na guerrilha anotadas em suas fichas da relação com a UNE, especialmente as de Ibiúna. Aliás, as fichas de Ibiúna recebem os dados de ações e IPMs anteriores, bem como os posteriores. Torna-se o polo identificador do grupo, mesmo quando os indivíduos não fazem mais parte dele, não pelo tempo, mas por terem abarcado num outro tipo de manifestação e/ou resistência (a luta armada). As fichas de indiciamento de 1968 estiveram ativas e abertas até 1982. No tocante aos militantes de base, que não tinham ligações com partidos ou grupos armados e não ocupavam cargos de liderança nas entidades estudantis, observa-se pelas fichas o controle nas atividades profissionais, na alteração de endereço residencial e no círculo social do qual participava. Para aqueles cuja única anotação derivava-se do IP 15/68, as formas de controle deixam de ser a prisão e a repressão para o controle dos passos da vida pessoal/profissional. Segue-se as fichas ${ }^{10}$ :

Ficha Catalográfica Simples nº 1: Augusto César Petta

Qualificação n ${ }^{\circ} 83$

Jaboticabal, 21-11-1946

Residência - Campinas

Estudante da Faculdade de Filosofia, da Universidade Católica de Campinas.

Indiciado no IP n15/68 (Ibiúna), por infração na Lei de Segurança Nacional, por ter participado do $30^{\circ}$ Congresso da Extinta UNE. Autuado á justiça militar aos 18/10/1968 23/02/1973 - Conforme oficio $n^{\circ} 358$, o epigrafado teve declara extinta sua punibilidade.

Ficha Catalográfica Simples nº 2: Caiuby Vieira Eugênio

Qualificação nº 100

São Paulo-SP

Residência Araraquara

2 números de $\mathrm{RG}$

Estudante da Faculdade de Odontologia de Araraquara.

Indiciado no IP n15/68 (Ibiúna), por infração na Lei de Segurança Nacional, por ter participado do $30^{\circ}$ Congresso da Extinta UNE. Autuado á justiça militar aos 18/10/1968.

${ }^{10}$ Numeração dada para a exposição no artigo. 
23/02/1973 - Conforme oficio $\mathrm{n}^{\mathrm{o}} 358$, o epigrafado teve declara extinta sua punibilidade, pela prescrição da ação penal, já transitada em julgado (autos remetidos à justiça militar 18/10/1968).

Informação Seccional de Araraquara: não registra antecedentes naquela Seccional. Colou grau em Odontologia na faculdade local em 16 de janeiro de 1970, estando radicado atualmente na cidade de Santos.

Ficha Catalográfica Simples no 3: Leopoldo Silva Castro

31 anos (21.6.1940)

Piau (Minas Gerais)

Residente em Araraquara

$\underline{\text { I - Informação da Ordem Política }}$

Estudante da Faculdade de Filosofia, Ciências e Letras de Araraquara.

Indiciado no IPM 15/68

23.2.1973 - Conforme oficio n. 358, extinção punibilidade.

II - Informação da seccional de Araraquara:

Não_registrou antecedentes naquela Seccional. Atualmente cursa o quarto ano do curso de química na Faculdade de Filosofia local, local em que se apurou que não se envolveu em assuntos políticos e nunca fez arte de Diretório acadêmico.

Ficha Catalográfica Simples nº 4: José Murari Bovo

Jaboticabal - Araraquara

27 anos $(3,3,1945)$

Estudante da Faculdade de Filosofia Ciências e Letras de Araraquara

Indiciado no IP 15/68

20/04/1970 Através do ofício n 155/70, de 15.4.70, o DB Coordenador da Secretaria de Educação solicitou informações sobre o fichado, de vez que é candidato ao cargo de instrutor junto ao departamento de Pedagogia e prestes a ser contratado pela faculdade de Filosofia, Ciências e Letras de Araraquara. Pelo ofício n 130/70 desta especializada, em 20/04/1970 foram prestadas as informações sobre os antecedentes políticos sociais do fichado, com o parecer de que o mesmo não poderá ser contratado pela referida faculdade.

23/02/1973 Conforme ofício n358 da $2^{\mathrm{a}}$. Auditoria, o epigrafado teve declarada extinta sua punibilidade, pela prescrição da ação penal, já transitada em julgado. 


\section{Informação da Seccional de Araraquara:}

Nada consta sobre o nominado, naquela seccional, foi Presidente do Centro Acadêmico da Faculdade de Filosofia local, onde se apurou haver sido ótimo aluno, convidado a integrar o corpo docente, o que não se realizou em virtude de haver participado do Congresso da Extinta UNE. Transferiu residência daquela cidade.

O tipo de nomenclatura dada ao estudante também é referência ao tipo de processo que se seguiu. Nominado e epigrafado normalmente dizem respeito ao indivíduo ainda não processado, enquanto fichado revela um indivíduo sob investigação, e marginado um indivíduo já condenado por algum processo ou que teve mandado de prisão expedido. A nomenclatura dada ao indivíduo cujas ações inscreviam-se no histórico DEOP indicava o tipo de investigação sob a qual estava. O mesmo acontecia com a identificação da ação individual na determinação do terrorista ou do subversivo, que parecem aleatórias, atribuídas a qualquer um que tivesse ligações com grupos de esquerda. Há inclusive o conceito ex-terrorista: uma pessoa podia deixar de ser terrorista de acordo com a avaliação do DOPS.

O exercício e possibilidade de manutenção da profissão parecem como uma óptica da repressão. Observa-se no segundo grupo um processo de sanção de sua participação no XXX Congresso refletido na negação de suas atribuições ou na impossibilidade de exercê-las, como consta na ficha de José Murari Bovo. Não era, entretanto, regra. A ficha de Azael Camargo demonstra que ele pode tomar posse de seu emprego numa universidade. Mas isso revela que o fichamento se torna uma marca pessoal indelével, passível do julgamento de outrem. Não necessariamente figura nas lembranças de cada ator.Há, ao mesmo tempo, autonomia e simbiose na produção de informações da Ordem Política e da Ordem Social: poderiam empreender as investigações e os inquéritos segundo suas próprias linhas de investigação, mas as suspeitas e resultados transitavam nos dois departamentos. As fichas se anexavam autos de apreensão que descreviam livros, revistas, folhetos detalhados, no mesmo esquema de identificação dos fichados do ME, identificadas também como "autos de colheita de material gráfico".

Entre os grupos de esquerda associados aos estudantes fichados, os mais recorrentes são a Dissidência Guanabara, ALN, VPR, Var-Palmares. Observou-se que a direção investigativa investigava as aproximações de estudantes com as organizações armadas como uma inclinação tática do grupo ME e não a partir de uma visão particularizada onde um indivíduo pertencente a uma "O" também militasse no ME. Os caminhos para a execução legal da punibilidade de alguma ação que afrontasse a LSN era a instalação de IPM pela 
DEOS que se remetia à Justiça Militar. Nestes termos, não havia uma denúncia, mas a Justiça definia se o procedimento seria instaurar um processo, expedir mandado de prisão preventiva ou prosseguir com as averiguações. As anotações individuais dos arquivos vão até 1972. A partir de 1973, tem um redirecionamento: são associadas ao grupo e, no grupo, anotadas informações individuais. A herança simbólica de 1968 transforma a participação de um individuo um movimento tal, passível de investigação pela Lei de segurança Nacional, em outra perspectiva: quem figura como componente do Movimento. Há, então, um reconhecimento de autonomia dos MEs e dos grupos armados: os elementos podiam sair ou serem presos, desaparecer, as o movimento permanecia auto-identificados pelo DOPS.

O dado mais importante da disposição dos arquivos, enquanto fonte viva e em constante transformação, é a mudança de olhar que se dá ao ME em dois momentos: quando os fichamentos e os IPMs em 1968 abrem o espaço para um novo modelo investigativo dos agentes do movimento, e depois, a partir de 1973, o entendimento do ME como grupo e sua investigação como tal. Essas duas determinações espelham a forma social com que simbolicamente o ME era interpretado, depreendendo das ações individuais os traços simbólicos que formam o grupo.

\section{Bibliografia}

ARQUIVO PÚBLICO DO ESTADO DE SÃO PAULO. Pastas dos índices Ordem Política e Ordem Social. Pesquisados entre 2009 e 2013.

AQUINO, Maria Aparecida de. As Vísceras expostas do Autoritarismo. Revista do Arquivo Público Mineiro, V.47, n. ${ }^{\circ} 1$, p. 21-39, 2006.

. et al. (Orgs.) No coração das trevas, o Deops-SP visto por dentro. São Paulo: Arquivo do Estado/Imprensa Oficial, 2001.

AUGUSTINHO, Aline M. N. A memória, o grupo e o ator. Ligações e tensões acerca da formação do conceito de identidade do Militante Estudantil de 1968. Tese de doutorado apresentada ao PPGS/UNESP FCLAr. Araraquara, São Paulo, 2015

Revisitando o Movimento Estudantil de 1968: a trajetória dos estudantes do interior paulista. Dissertação de Mestrado, PPGPol- UFSCar. São Carlos, 2010.

ÁVILLA, Mariela Cecilia; ALFARO, Tuillang Yuing. Aproximaciones foucaulteanas para pensar la tortura en el Cono Sur latinoamericano: una revisión. Izquierdas, 31, Diciembre 2016:1-18

BRASIL. Comissão Nacional da Verdade. Relatório: textos temáticos / Comissão Nacional da Verdade. - Brasília: CNV, 2014. 416 p. - (Relatório da Comissão Nacional da Verdade; v. 1) 
BRASIL. Comissão Nacional da Verdade. Relatório: textos temáticos / Comissão Nacional da Verdade. - Brasília: CNV, 2014. 416 p. - (Relatório da Comissão Nacional da Verdade; v. 3)

FARIA, Daniel Barbosa Andrade de. Baderneiros, arruaceiros, guerrilheiros: um acontecimento na transição democrática. Estudos Históricos Rio de Janeiro, vol 31, nº 63 , p. 49-70, janeiro-abril 2018

FORACCHI, M. M. A Juventude na Sociedade Moderna. São Paulo, Editora USP, 1972.

O Estudante e a Transformação da Sociedade Brasileira. São Paulo, Companhia Editora Nacional, 1977

GARAPON, Antoine. Crimes que não se podem punir sem perdoar: para uma Justiça Internacional. Tradução de Pedro Henriques. Lisboa: Instituto Piaget, 2004.

MARTINS FILHO, J. R. (org). 1968 faz 30 anos. Campinas: Mercado de Letras, São Carlos: Editora UFSCar, 1998.

Movimento Estudantil e Ditadura Militar 1964-1968. Campinas: Papirus, 1987.

\section{Sites Consultados}

Arquivo Público do Estado de São Paulo.

http://www.arquivoestado.sp.gov.br/memrev/memrev_pesquisa.php

http://www.arquivoestado.sp.gov.br/memrev/memrev_consulta.php

Recebido em setembro de 2018

Aprovado em novembro de 2018 